\title{
Design and Development of IoT Device to Measure Quality of Water
}

\author{
Chandrappa S and Dharmanna L \\ Computer Science and Engineering, S. D. M Institute of Technology, Ujire, India \\ Email: \{chandrucs21, dharmannasdmit\}@gmail.com
}

\author{
Shyama Srivatsa Bhatta U V, Sudeeksha Chiploonkar M, Suraksha M N and Thrupthi S \\ Computer Science and Engineering, S. D. M Institute of Technology, Ujire, India
}

\begin{abstract}
The conventional method of measuring the quality of water is to take the samples manually and send it to laboratory for analysis. This technique is time overwhelming and not economical. Also it is not feasible to take the water sample to the laboratory after every hour for measuring its quality. To overcome from these problems a new system is proposed in this work. This water quality measuring system will measure the essential qualities of water in real time. The proposed system consists of multiple sensors to measure the standard of water, Raspberry Pi 2 and Ethernet Local Area Network (LAN) to send the information to the controlling center. It's a real time system which is able to endlessly measure the standard of water and send the measured values to the controlling center in each predefined time. The system relies on sensors, Raspberry Pi 2 and Internet.
\end{abstract}

Index Terms - Raspberry Pi 2, water, sensors, turbidity, $\mathrm{pH}$, Temperature, Internet of Things (IoT)

\section{INTRODUCTION}

Water is a resource of prime importance. Life on the earth would not have been evolved without water. The availability of high quality water is a key determinant for human, animal and plant survival. Water quality refers to the chemical, physical, biological, and radiological characteristics of water [15]. It is a measure of the condition of water relative to the requirements of one or more biotic species and or to any human need or purpose. It is most frequently used by reference to a set of standards against which compliance can be assessed. The most common standards used to assess water quality relate to health of ecosystems, safety of human contact and drinking water. The quality of water is determined by many factors that include total dissolved solid, conductivity, $\mathrm{pH}$, turbidity and temperature. Many factories, power plants, nuclear reactors and petroleum refineries requires large amount of water for cooling purpose. The heated water is discharged into rivers and lakes results in increasing of water temperature. When water temperature becomes too high, it effects on organisms that are living in the water such as fishes. That means organisms that are living in water may die or may suffer from variety of ill effects. High Water temperature also reduces the solubility of oxygen and increases the toxicity of ammonia which also affects living beings present in the water. For these reasons, it is one of important parameter in water quality measurement and it is also important to protect water from unnecessary warming.

Turbidity is the cloudiness of a fluid caused by large numbers of individual particles [16]. Turbidity in water is caused by Human activities that disturb the land, such as construction, mining and agriculture, can lead to high sediment levels entering water bodies during rain storms. Urbanized areas also cause large amounts of turbidity to nearby water bodies from paved surfaces such as roads, and bridges [9]. Certain industries such as petroleum refineries, mining and coal recovery generate the very high levels of turbidity from colloidal particles. In drinking water, the higher the turbidity level means higher the risk that people may suffer from gastrointestinal diseases [10]. Therefore, turbidity is another important key parameter of water quality measurement.

Another important key factor for water quality measurement is $\mathrm{pH}$. It is a measure of whether water is hard or soft. The range goes from 0 - 14, with 7 being neutral. $\mathrm{pH}$ of less than 7 indicates acidity, whereas a $\mathrm{pH}$ of greater than 7 indicates a base [11]. $\mathrm{pH}$ is really a measure of the relative amount of free hydrogen (acidity) and hydroxyl (base) ions in the water. Water that has $\mathrm{pH}$ value less than 7 indicates more hydrogen ions, whereas water that has $\mathrm{pH}$ value greater than 7 indicates more hydroxyl ions. If the $\mathrm{pH}$ value of water is too high or too low, aquatic organisms living within it will die and is not suitable water for drinking.

The old method of measuring the quality of water which is in use today is not an economical as well as not reliable, time consuming and not accurate. So there is a necessity to develop a system that is accurate, robust and able to cope with the real time environment.

This work presents a effective use of low-cost, robust, real time and easily deployable sensors for measuring the quality of water. In this real time IoT system, the water quality is measured using sensors such as digital temperature sensor, $\mathrm{pH}$ sensor, Turbidity sensor and Raspberry Pi 2. The sensors measure the quality of water by considering the $\mathrm{pH}$, temperature, turbidity of the water. The qualities which are measured by sensors are transmitted to Raspberry Pi 2 and then it is transmitted to 
controlling centre through internet. These continuously measured values are stored in the repository. Measured values are displayed on LCD screen. This system allows the user to access the data from database through website and provides the advantage of improved efficiency, accuracy and low price.

This paper is structured as follows; an introduction of the water and parameters used to measure the quality of water is given in this section. The System Design and Development section gives the details of all the sensors and methods used in the development of the system. The Results section presents the data gathered in the laboratory and from the proposed system. The Conclusions section reviews the paper, highlighting the ability of the low-cost sensors to detect quality of water.

\section{RELATED WORK}

Li Zhenan et.al [1]., introduced an intelligent water quality and control system based on wireless sensor networks to measure the quality of water. This system used the mobile wireless sensors to monitor water quality in a remote fashion and can detect pollutant location. Wireless controlled UAVs are integrated for the marking, separation and removal of pollutant. The technical challenges such as sensor selection and wireless control are addressed with customized novel algorithms. But UAV control algorithm is not efficient method for control wireless systems.

Mithila Barabde1 et.al [2], proposed new system for water quality measurement. This system is based on wireless sensor network (WSN) which makes use of ZigBee. Another important fact of this system is the easy installation of the system that is the base station can be placed at the local residence close to the target area and the monitoring task can be done by any person with very less training at the beginning of the system installation. One important aspect is the system should work in different environment in more effective way, but using this system it is difficult to get reliable results in every situation.

A. Fredrick et.al [3], developed new prototype based on IEEE 802.15.2.4 and solar energy for water quality monitoring is described. The prototype used ECHERP routing protocol for energy conservation purposes and solar panels are used instead of batteries to ensure the system will last in a long period of time. But evidently solar energy technologies remain to be very costly alternative. The fabrication of solar modules and their installation entail large amount of resources. Main drawbacks of this system are costly and difficult to deploy the system.

Akila U et.al [4], presented a water quality monitoring system based on wireless sensor network. The system consisting the base station and several sensor nodes. In the node side, water quality data was collected by sensors such as $\mathrm{pH}$ and Temperature. Here authors used ARDUINO UNO 3 as hardware component to interface between sensors and GSM module to develop the system. Drawbacks of this system are measures only $\mathrm{pH}$ and
Temperature of water. It will not measure Turbidity of water and data storage module is not presented in this work.

Thamarai Selvi D et.al [5], presented a design of real time monitoring of drinking water quality system at consumer sites. The proposed system consist of several in-pipe water quality sensors. These are low power, lightweight and capable to process of data. The System is validated to enable these sensor nodes to make decisions and trigger alarms when anomalies are detected. This automated water utility billing system will overcome the difficulties in existing Water distribution system. The total costing of the meters is supposed to reduce so as the system will be economical along with power consumption reduction will be achieved by programming. Proposed system as per user requirement that is for monthly billing cycle it will be in active mode once in a month and rest of the time it will be sleep mode. But these systems are bulky and remain cost prohibitive for large scale deployments such systems can take frequent samples of the water quality at a very limited number of locations.

Amruta Boyne et.al [6], did the detailed study of embedded PLC and its pros and cons. Later, they developed a new system to measure the quality of water. extra hardware's like camera, LCD, SD card, Ethernet, LAN with many allied techniques were used in that system. The sensors $\mathrm{pH}$ and TDS (Total Dissolved Salt) will be kept in the river water surface and the data captured by the sensor will be given to Arm cortex M3 Microcontroller and then data is captured and transmitted to an authentic source. After calculating the vital inference from the sensed data it's analysed. But microcontroller is specific to particular application and also this system has more complex architecture than the system which is developed using Raspberry Pi 2.

From the survey, following are the drawbacks identified in the existing systems:

- Investment for the system is high.

- Size of the system is large

- The control system is not user friendly

- The systems are not real time and not able to measure the quality of water efficiently

To overcome these drawbacks, our system uses simple devices that are small in size. The investment for the system is comparatively very less. The mechanism we implemented is too simple and effective. This system works with an internet connection. The system will measure the temperature, $\mathrm{pH}$ and turbidity of water in real time. This system is user friendly which sends text messages for registered user if predefined values of water exceeded.

\section{SYSTEM DESIGN AND DEVELOPMENT}

The water quality measurement system uses $\mathrm{pH}$, turbidity and temperature sensors to measure the standard of water. These sensors measure the corresponding values 
in the water. These three sensors are connected to Raspberry Pi. The Measured information send to Raspberry Pi. the output of the $\mathrm{pH}$ sensor is analogue in nature, so, it is converted in to digital using ADC (analog to digital converter). System uses LAN/wireless network for communication with the control centre. It's a real time system and it doesn't required any man machine interaction. The systematic arrangements of the components are shown in the Figure 1.

The Raspberry $\mathrm{Pi}$ is a small sized single-board computer. All Raspberry Pis included the same Video Core IV GPU and either a single core ARMv6compatible CPU or an ARMv7-compatible quad-core one. $\mathrm{Pi}$ is also included the $1 \mathrm{~GB}$ of RAM or a Micro SDHC one for boot media [12]. In this work Raspberry Pi 2 model is used. The $\mathrm{pH}$ sensor, Temperature sensor and Turbidity sensor are connected to Raspberry Pi as shown in the Figure 1. Python programming language is used to connect various sensors. PHP and html languages are used for Graphical User Interface. For information storage and retrieval MySql is used.

The $\mathrm{pH}$ Electrode $\mathrm{BNC}$ is used to measure the $\mathrm{pH}$ value of the water. It is a gel-filled combination $\mathrm{pH}$ electrode designed to make measurements in the $\mathrm{pH}$ range of 0 to 14.The body that extends below the glass sensing bulb of the electrode makes this probe ideal for making measurements in the environment.

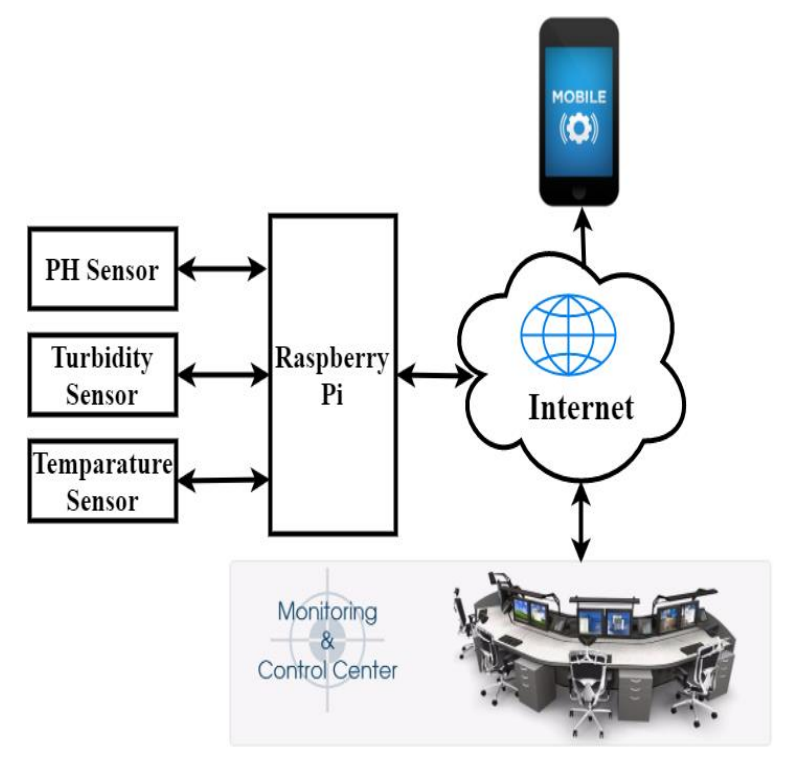

Fig.1. System Structure

Turbidity is the phenomenon where by a specific portion of a light beam passing through a liquid medium is deflected from undissolved particles. Turbidity sensors are used to measure water quality in rivers and streams, wastewater and effluent measurements, control instrumentation for settling ponds, sediment transport research and laboratory measurements. In this work SKU: SEN0189 Turbidity sensor [13] is used to measure the turbidity of the water. This sensor measures turbidity of water in form of analog signal and this signal is goes to ADC where the signal is converted into digital and it is send to Raspberry $\mathrm{Pi}$. Pi process the signal and code written in the Pi convert the digital signal into NTU.

The DS18B20 Temperature sensor [14] is used to measure the temperature of water. It is a waterproofed version and it good up to $125^{\circ} \mathrm{C}$. It is digital, so you don't get any signal degradation even over long distances. The sensor has 3 wires: red (VCC), black (GND) and yellow (DATA). Connect the red to $+5 \mathrm{~V}$, the black to GND and the yellow to the digital pin D10 of Pi. Then put a $4.7 \mathrm{k}$ ohm resistor between yellow wire and $+5 \mathrm{~V}$. We have added a $4.7 \mathrm{~K}$ resistor, which is required as a pull up from the DATA to VCC line when using the sensor. It is a digital sensor so it is directly connected to Raspberry Pi.

In this work we also implemented data storage facility. Here, Pi will sent the sensors data to controlling center. This system also provides SMS notification facility for authorized users using SMS gateway. An SMS gateway allows a Pi to send Short Message Service (SMS) to a telecommunications network using web browser to people within the limit served by that gateway. An SMS gateway can also serve as an international gateway for users with roaming capability, allowing SMS communication away from the home network. In this work Way2SMS.com is used as SMS gateway to notify the registered users about sudden water quality variations that are measured by the sensors as show in Figure 2.

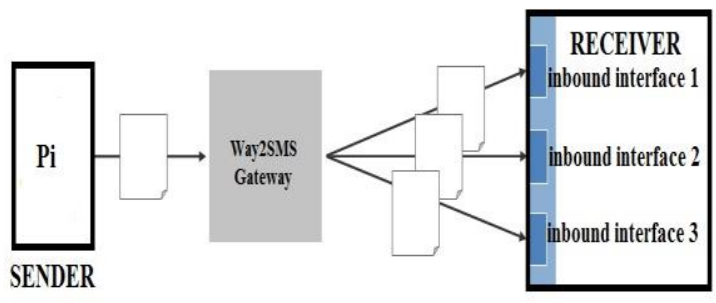

Fig.2. SMS Transmission

\section{a. Measurement of Temperature of Water using temperature sensor}

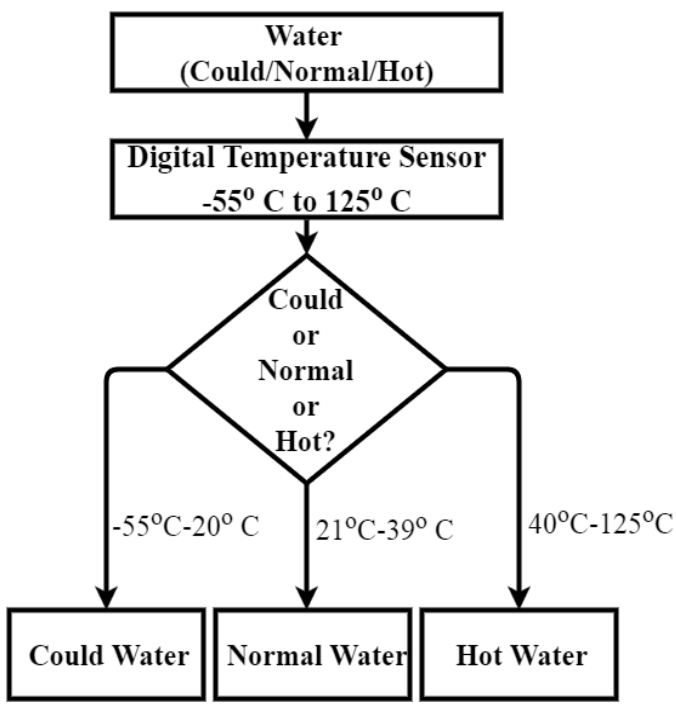

Fig.3. Flow Chart of Water Temperature Measurement 
Figure 3 shows how sensor measuring the water temperature in the range from $-55^{\circ} \mathrm{C}$ to $125^{\circ} \mathrm{C}$. Basically water temperature is classified into cold, normal and hot based on its temperature. If the temperature is in the range from $-55^{\circ} \mathrm{C}$ to $20^{\circ} \mathrm{C}$ is considered as cold water, from $21^{\circ} \mathrm{C}$ to $39^{\circ} \mathrm{C}$ is considered as normal water and from $40^{\circ} \mathrm{C}$ to $125^{\circ} \mathrm{C}$ is treated as hot water.

\section{b. Water $\mathrm{pH}$ value measurement using $\mathrm{pH}$ sensor}

The $\mathrm{pH}$ sensor measures hydrogen potential in the water that ranges between 0 and 14. Based on the $\mathrm{pH}$ value, water is classified as acidic, normal and basic. If the value is below 7 it is considered as acidic, above 7 as basic and 7 as normal or good water. In acidic, it is again classified as low acidic (3 to 6) and high acidic (0 to 2). In the same way basic water is also classified into two types. They are low basic ( 8 to 10 ) and high basic (11 to 14). The Figure 4 shows the flow chart of $\mathrm{pH}$ value measurement.

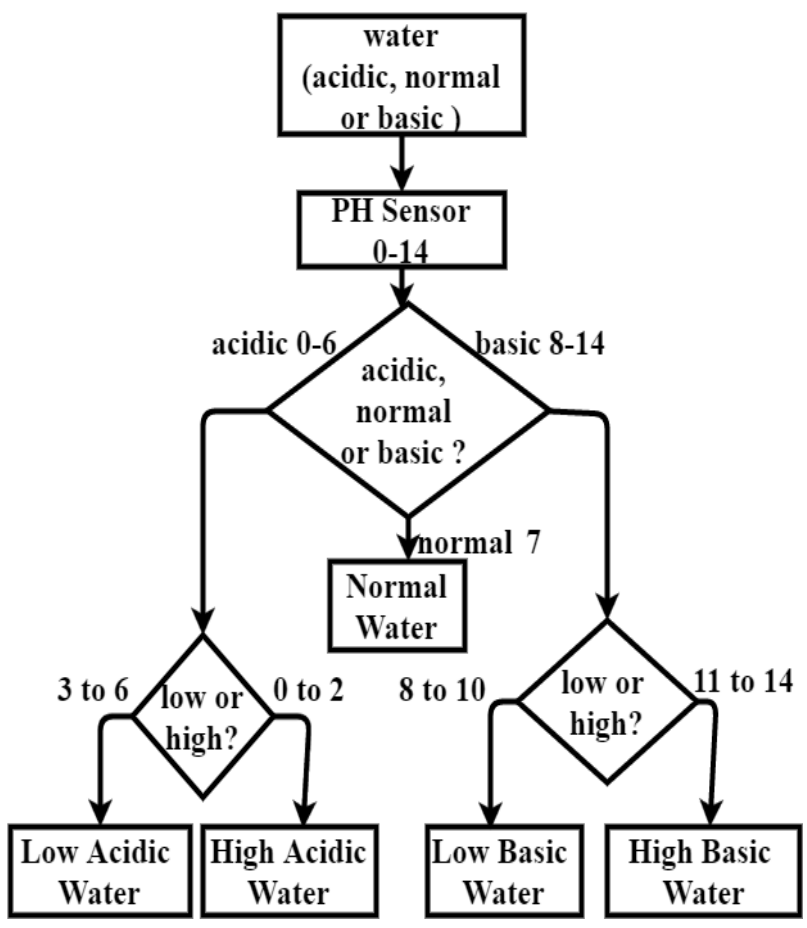

Fig.4. Flow Chart of PH Value Measurement

\section{c. Measurement of Turbidity of Water}

The turbidity of water is its clarity. If any mud, slit or sand particles etc. are mixed with the water, its quality varies. According to the water quality norms, normal water ranges from 0 NTU (Nephelometric Turbidity Units) to $5 \mathrm{NTU}$ and also maximum of up to $25 \mathrm{NTU}$ is permissible. If the water goes over 26 NTU up to 3000 NTU it is classified as turbid or mud mixed water. Figure 5 shows flow chart of water classification based on turbidity value of water.

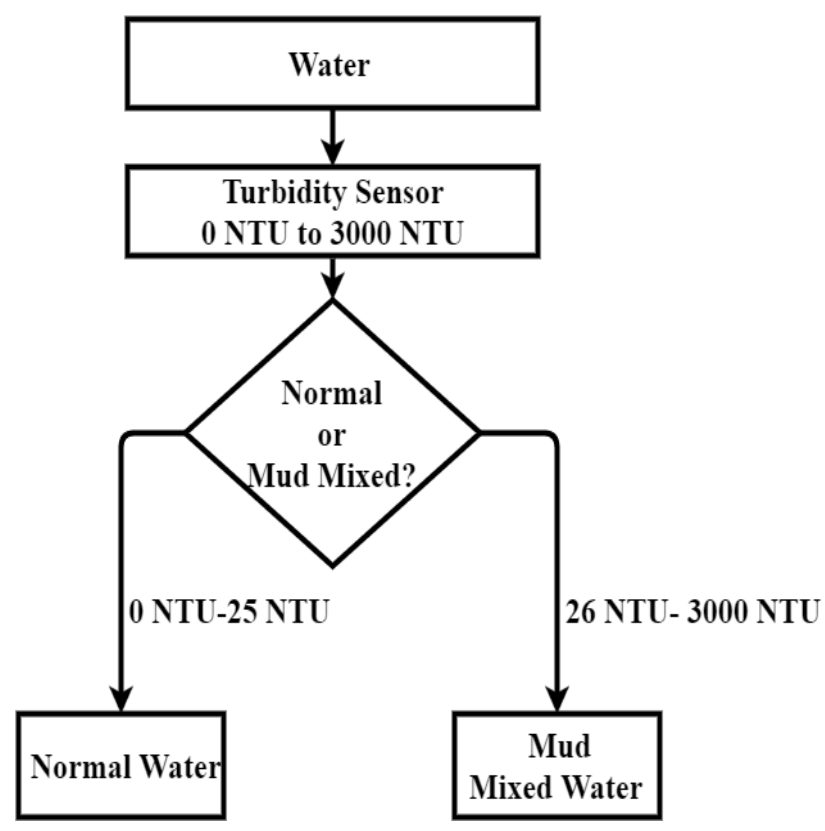

Fig.5. Flow Chart of Turbidity Value Measurement

The Algorithm for water quality measurements is as follows.

Step 1: Start.

Step 2: turn on all sensors.

Step 3: read the sensors data after every 10 minutes.

Step 4: store the data in database.

Step 5: if $\left\{\right.$ temperature is $<20^{\circ} \mathrm{C}$ or $\left.>40^{\circ} \mathrm{C}\right\} \mid$ turbidity is $>26 \mathrm{NTU}\} \mid\{\mathrm{pH}$ is $<7$ or $>8.5\}$ then go to Step 6 else go to step 3

Step 6: send appropriate message to registered users then go to step 3 .

\section{RESULT AND ANALYSIS}

Three sensors (Temperature, Turbidity, and $\mathrm{pH}$ ) are connected to Raspberry Pi as shown in the Figure 6. The digital temperature sensor DS18B20, which is a one wire digital device. So, it is directly connected to Raspberry Pi along with a $4.7 \mathrm{k} \mathrm{Ohm}$ resistor which is required as a pull up from the DATA to VCC line when using the sensor. The turbidity sensor SEN-0189 is an analog sensor which senses the clarity of the water. Raspberry $\mathrm{Pi}$ supports only digital sensors and it will take only digital values. Therefore in this approach, an analog to digital converter is used (ADC- MCP3008) to convert analog signals into digital signals. Sensor is connected to channel 1 of the ADC to convert the analog value to digital. Later, digital value input to Raspberry $\mathrm{Pi}$. Similarly, $\mathrm{pH}$ electrode BNC-E201 is also an analog sensor, therefore this sensor is connected to channel 2 of ADC. Here, turbidity sensor and $\mathrm{pH}$ electrode are connected to ADC. ADC is connected to Raspberry $\mathrm{Pi}$. All the three sensors in the following scenario measuring the quality of normal tap water. The Ethernet cable is connected to Raspberry Pi to send the information control center. The breadboard is used for the connections. 


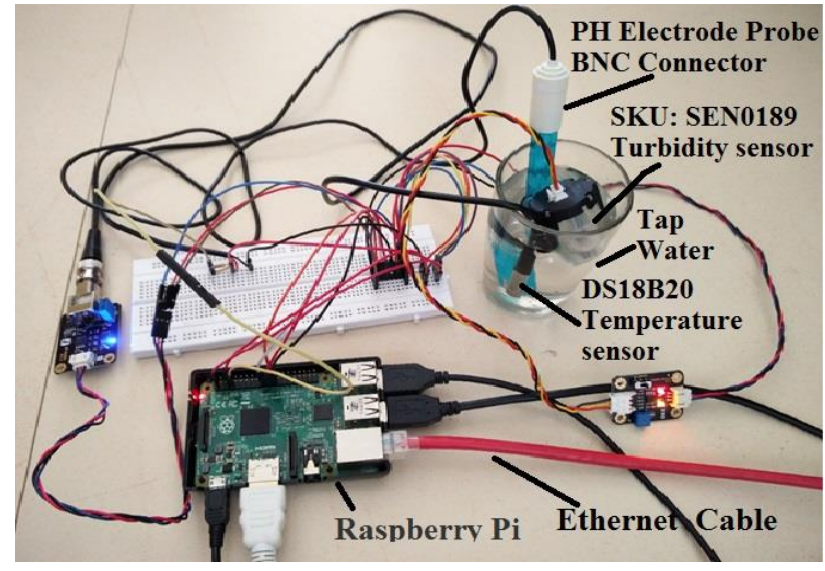

Fig.6. Connections of Sensors to Pi

The Figure 7 shows the readings of all the three sensors of normal tap water. The Temperature, $\mathrm{pH}$ and Turbidity values of the water is displayed along with its measuring units in the Terminal (Command Prompt) of the Raspberry Pi. It also shows the SMS notification sent to the registered user when there is a variation in the water quality.

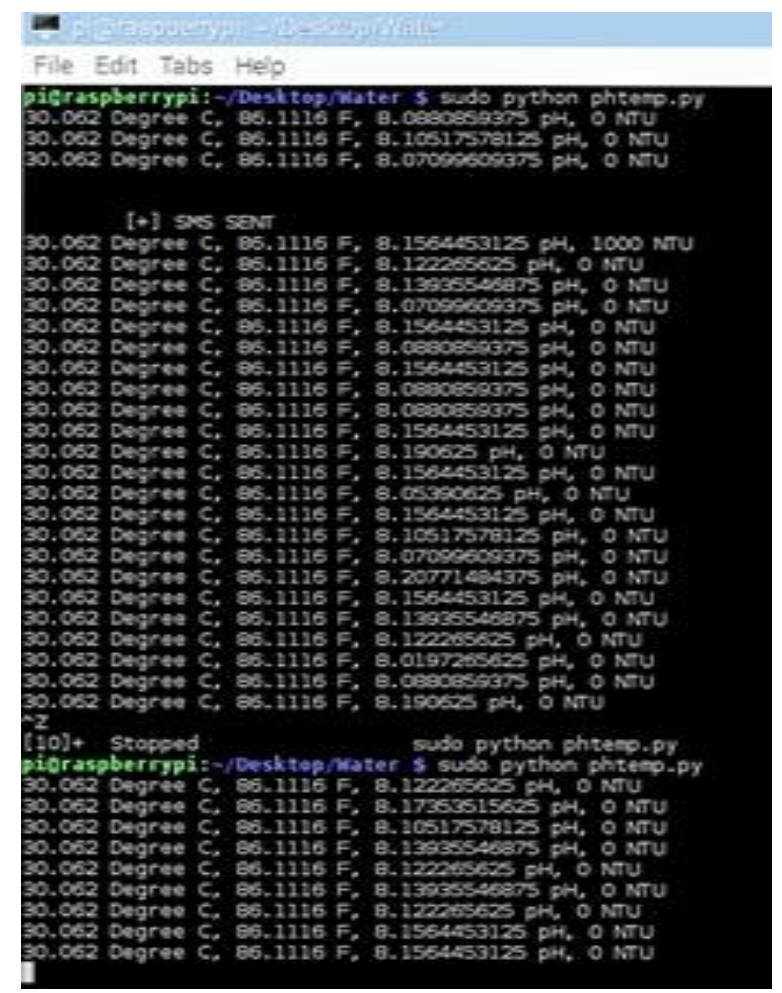

Fig.7. Readings from Sensors

The Figure 8 shows the SMS notifications sent to the registered users of the device to know the quality of water. Here, users' needs provide their mobile numbers to get notifications from the Raspberry Pi device. There are different notifications related to water temperature, $\mathrm{pH}$ and turbidity are send to registered users via SMS gateway. These notifications are received by the user when water quality is varied suddenly than some prefixed threshold values.

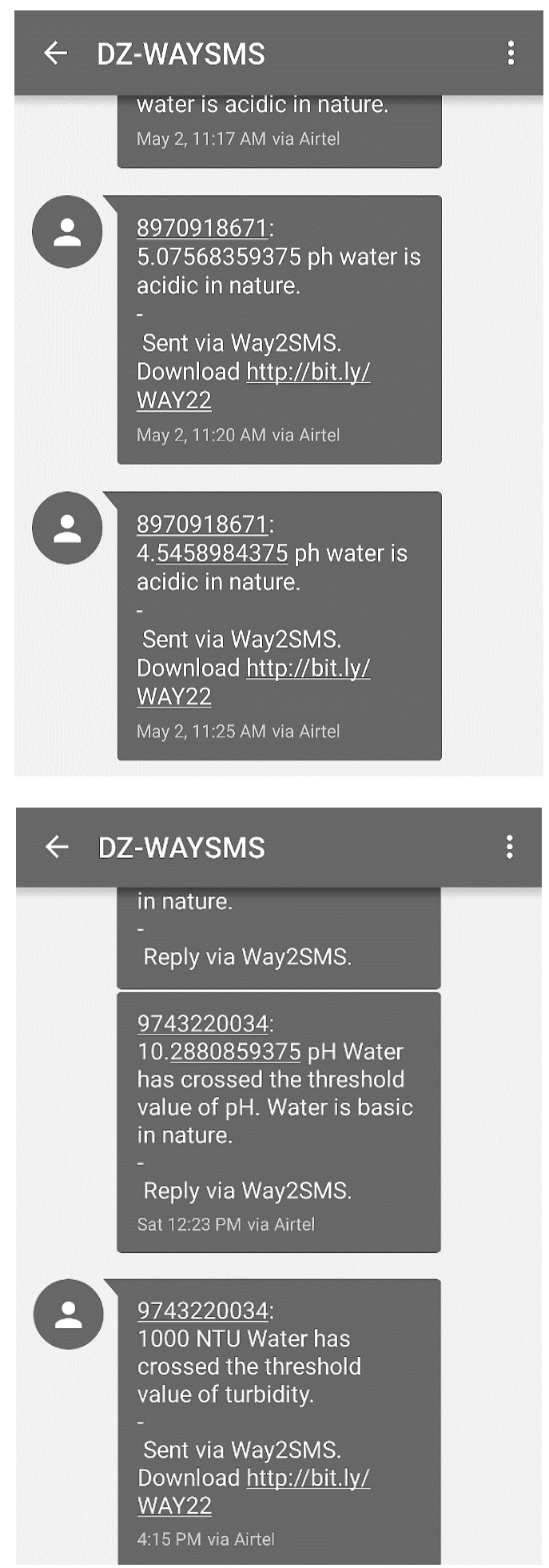




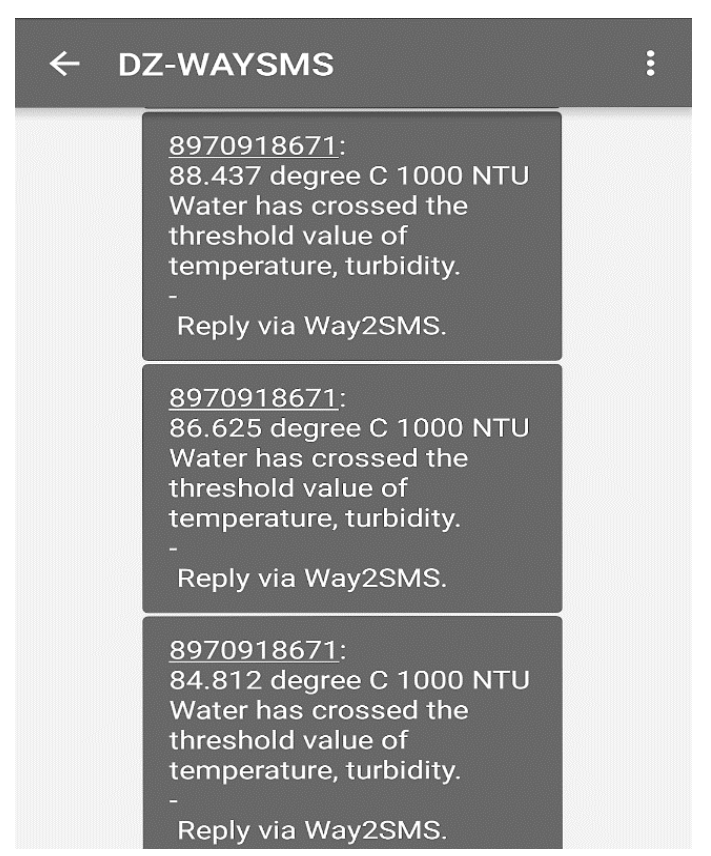

Fig.8. SMS Notifications

The Figure 9 shows the data retrieved from the database. It will help the users to know about water quality at any time and from anywhere. This page also provides an option to get the stored water quality information based on the specific date.

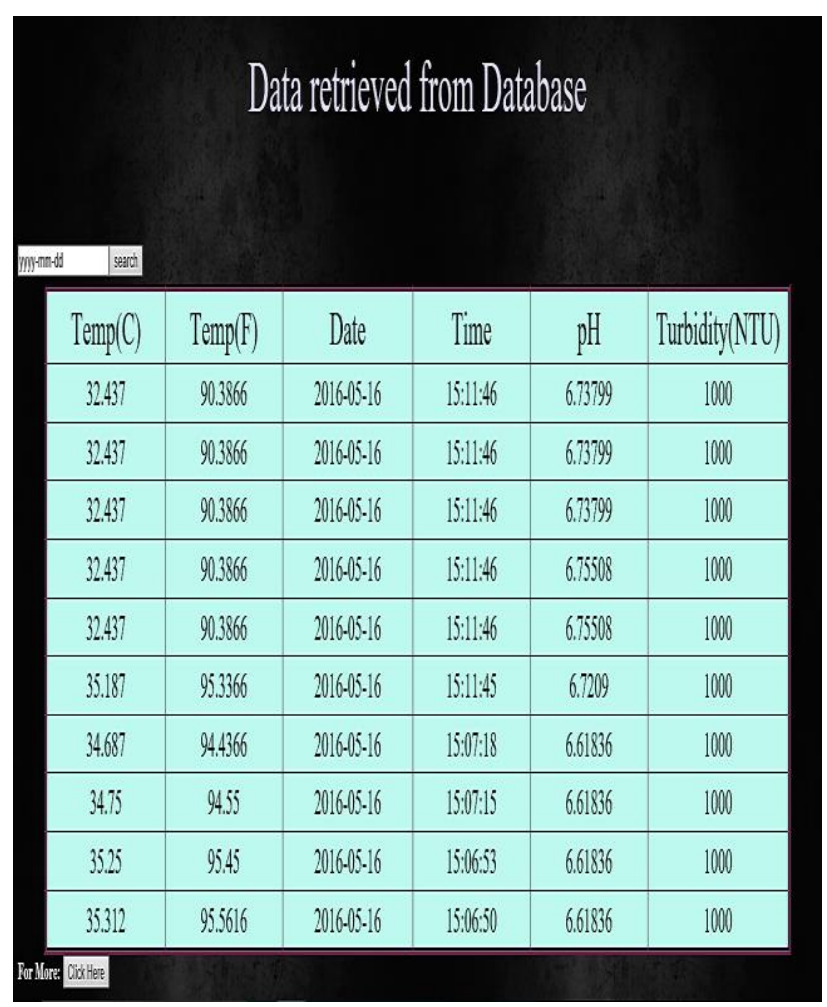

Fig.9. Data Retrieved from Database

The experimental outcomes obtained for various input and their comparisons are shown in the table 1. Table shows the input water type, measurement parameter considered. Laboratory value and system measured value.
Initially, various types of water samples are considered for testing the proposed system. These samples of water are tested in SDM institute of Technology chemistry laboratory and results are noted. Later, same samples are tested with our developed device and results are once again noted separately. Here, we considered one parameter at a time and we obtained almost same result from developed device compared to laboratory result. This shows that proposed system can be used to measure the quality of water in real time.

Table 1. Comparison of proposed system result with laboratory results

\begin{tabular}{|c|c|c|c|c|}
\hline Sl.no & Input & Measurement & $\begin{array}{c}\text { Laboratory } \\
\text { value }\end{array}$ & $\begin{array}{c}\text { System } \\
\text { value }\end{array}$ \\
\hline 1 & $\begin{array}{l}\text { Cold } \\
\text { Water }\end{array}$ & Temperature & 20 & 20.083 \\
\hline 2 & $\begin{array}{l}\text { Normal } \\
\text { Water }\end{array}$ & Temperature & 30 & 30.062 \\
\hline 3 & $\begin{array}{c}\text { Hot } \\
\text { Water }\end{array}$ & Temperature & 58 & 58.103 \\
\hline 4 & $\begin{array}{c}\text { High } \\
\text { Acidic } \\
\text { Water } \\
\end{array}$ & $\mathrm{pH}$ & 1.58 & 2.008 \\
\hline 5 & $\begin{array}{c}\text { Low } \\
\text { Acidic } \\
\text { Water }\end{array}$ & $\mathrm{pH}$ & 5.7 & 6.129 \\
\hline 6 & $\begin{array}{c}\text { Normal } \\
\text { Water }\end{array}$ & $\mathrm{pH}$ & 7.6 & 8.122 \\
\hline 7 & $\begin{array}{c}\text { Low } \\
\text { Basic } \\
\text { Water }\end{array}$ & $\mathrm{pH}$ & 9 & 9.309 \\
\hline 8 & $\begin{array}{l}\text { High } \\
\text { Basic } \\
\text { Water }\end{array}$ & $\mathrm{pH}$ & 12 & 12.403 \\
\hline 9 & $\begin{array}{c}\text { Mud } \\
\text { Mixed } \\
\text { Water }\end{array}$ & Turbidity & 1005 & 1000 \\
\hline 10 & $\begin{array}{c}\text { Normal } \\
\text { Water }\end{array}$ & Turbidity & 2 & 0 \\
\hline
\end{tabular}

\section{CONCLUSION}

This work focused on analyzing the water quality with high performance, real time, accurate and low cost. This system can be used to measure the quality of drinking water, river water, sea water etc. Water quality is determined by considering several parameters like $\mathrm{pH}$, temperature, turbidity, Total Dissolved Solids (TDS), conductivity etc. In this work $\mathrm{pH}$, temperature and turbidity parameters are considered to measure the quality of water. These three parameters of the water are measured with the help of Raspberry Pi and sensors. The proposed system measures the temperature, turbidity and $\mathrm{pH}$ of water for every 5 minutes and these measured values are stored in database. based on the threshold values set, Raspberry Pi notifies the registered user by sending text SMS with the values and these values can also be retrieved through website.

In future, the parameters like Total Dissolved Solids (TDS), conductivity, hardness, chloride, ammonia, iron, fluoride etc are also considering for water quality measurement and these values are used to check the purity of water for many purposes such as drinking water and daily requirements. 


\section{REFERENCES}

[1] Li Zhenan, Wang Kai, Liu Bo, "Sensor-Network based Intelligent Water Quality Monitoring and Control", International Journal of Advanced Research in Computer Engineering \&Technology, Volume 2, Issue 4, April 2013, ISSN: $2278-1323$

[2] Mithila Barabde1, Shruti Danve, "Real Time Water Quality Monitoring System", International Journal of Innovative Research in Computer and Communication Engineering, June 2015, ISSN: 2320 - 9801.

[3] A. Fredrick Romanus Ishengoma, "A Novel Design of IEEE 802.15.4 and Solar Based Autonomous Water Quality Monitoring Prototype using ECHERP", International journal of Computer Science \& Network Solutions, January 2014, Volume 2, ISSN: 2345-3397.

[4] Akila U, Elackiaselvi R, Mahaeshwari R, Shunmugavalli K, Mrs .T. Prathiba, "Industrial sewage water quality monitoring system", International Journal of Advanced Engineering Research \& General Science, Volume 3, Issue 2, March-April, 2015, ISSN: 2091-2730.

[5] Thamarai Selvi D, Anitha S.R, "Potable Water Quality Monitoring and Automatic Billing System", International Journal of Advanced Research in Electrical, Electronics and Instrumentation Engineering, Volume 4, Issue 4, April 2015.

[6] Amruta Boyne, Prof. S. N. Kulkarni, "Build out of Embedded PLC for Water Quality Monitoring", International Journal of Advanced Research in Computer Science and Software Engineering, Volume 5, Issue 6, June 2015, ISSN: 2277 128X

[7] Mr. Akram Salim Pathan, Mr. G.R. Gandhe, "Design of Object-Oriented Water Quality Software System A Case Study of Upper Godavari River Paithan, Aurangabad (MS) India", International Journal of Scientific and Research Publications, Volume 3, Issue 6, June 2013, ISSN: 22503153

[8] Feng Zhang, "Underwater Sensor Networks for Water Quality Monitoring".

[9] U.S. Environmental Protection Agency (EPA). Washington, D.C. "National Management Measures to Control Nonpoint Source Pollution from Urban Areas." Chapters 7 and 8. Document No. EPA 841-B-05-004. November 2005.

[10] A.G. Mann, C.C. Tam, C.D. Higgins, \& L.C. Lodrigues. (2007). The association between drinking water turbidity and gastrointestinal illness: a systematic review. $B M C$ Public Health. 7(256): 1 - 7.

[11] http://crest.cuny.edu/hires/wpcontent/uploads/2014/08/HIR ES_Experiment_Module_Water1.pdf.

[12] https://en.wikipedia.org/wiki/Raspberry_Pi

[13] https://www.dfrobot.com/wiki/index.php/Turbidity_sensor _SKU:_SEN0189

[14] http://datasheets.maximintegrated.com/en/ds/DS18B20.pdf

[15] Diersing, Nancy (2009). "Water Quality: Frequently Asked Questions." Florida Brooks National Marine Sanctuary, Key West, FL.

[16] https://en.wikipedia.org/wiki/Turbidity

\section{Authors' Profiles}

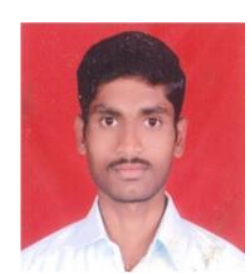

Chandrappa $\mathbf{S}$ was born in Channagiri city, India. He received B.E degree in Computer science and Engineering from SJM Institute of technology, affiliated college of VTU, Chitradurga, Karnataka, India in 2006 and M.Tech degree in Computer Science and Engineering from NMAM Institute of technology, Nitte, Karnataka, India. Since 2011, He is working as Assistant Professor in Computer science and Engineering Department at SDM Institute of technology, Ujire, Karnataka. His research interests include Networking, Internet of Things and Medical Image Processing. He has published around 05 papers in reputed Journals and Conferences.

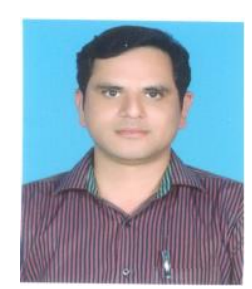

Dharmanna Lamani, is currently HOD of information science and engineering, SDM Institute of technology, Ujire, Karnataka. He obtained M.Tech degree from VTU, Belagavi. He was awarded Ph.D. in computer science and engineering from VTU, Belagavi. His research interests includes Medical Image Processing, Embedded System design, Pattern Recognition and Computer Networking. He has published around 15 papers in reputed Journals and Conferences.

How to cite this paper: Chandrappa S, Dharmanna L, Shyama Srivatsa Bhatta U V, Sudeeksha Chiploonkar M, Suraksha M N, Thrupthi S,"Design and Development of IoT Device to Measure Quality of Water", International Journal of Modern Education and Computer Science(IJMECS), Vol.9, No.4, pp.50-56, 2017.DOI: 10.5815/ijmecs.2017.04.06 